\title{
Mesenchymal Stem Cell-Based Immunomodulation in Allogeneic Heterotopic Heart-Lung Transplantation
}

\section{Biancamaria Longoni ${ }^{1 *}$, Erzsèbet Szilàgyi ${ }^{1}$, Lorenza Puviani ${ }^{2}$, Benedetta Mazzanti ${ }^{3}$, Giacomo Timoteo Paoli', Serena Urbani ${ }^{3}$, Paola Quaranta', Sara Antonini' ${ }^{1}$, Sergio Tripodi ${ }^{4}$, Marcella Cintorino ${ }^{4}$, Riccardo Saccardi ${ }^{3}$, Bruno Nardo $^{2}$ and Franco Mosca ${ }^{1}$}

${ }^{1}$ Department of Oncology, Transplantation and New Technology in Medicine, University of Pisa, Pisa, Italy

${ }^{2}$ Department of Surgery, Bologna University, St. Orsola Hospital, Bologna, Italy

${ }^{3}$ Bone Marrow Transplant Unit, Hematology Unit, Careggi Hospital, Florence, Italy

${ }^{4}$ Department of Human Pathology and Oncology, Pathology Section, University of Siena, Siena, Italy

\begin{abstract}
Mesenchymal stem cells are able to differentiate in various cell lineages and they have shown immunomodulatory properties in vitro, altering the cytokine secretion profile of $\mathrm{T}$ helper, $\mathrm{T}$ effector and dendritic cells and stimulating natural killer cells towards an anti-inflammatory and tolerant phenotype. In vivo they prolong skin allograft survival and may decrease graft-versus-host disease after hematopoietic stem cell transplants. In this work we studied the effects of mesenchymal stem cell treatment in an allogeneic heterotopic heart-lung transplant model.
\end{abstract}

The following experimental groups were formed: A) Control B) Immunosuppressive therapy (Cyclosporine A) C) Mesenchymal stem-cell intravenous infusion D) Mesenchymal stem-cell infusion plus immunosuppressive treatment.

The infusion of mesenchymal stem cells improved the mean graft survival up to $14.5 \pm 3.7$ days with respect to the control group ( $3 \pm 0.6$ days). Treatment with Cyclosporine A plus mesenchymal stem cells (group D) produced a mean survival time of $18.25 \pm 4.9$ days, and was not significantly different to the results for group $B(21.75 \pm 3.5$ days). Furthermore, in the immunosuppressive treatment and the mesenchymal stem cell treatment, histological analysis revealed a reduction in the grade of rejection in heart and lung grafts. This decrease was most significant in group D.

In conclusion, mesenchymal stem cells alone or in combination with Cyclosporine A were able to prolong graft survival time. These data suggest that, in vivo, mesenchymal stem cells retain their ability, already shown in vitro, to suppress lymphocyte activation and proliferation.

Keywords: Immunosuppression; Graft; Rejection; Organ Transplant; Cyclosporine A

Abbreviations: 7-ADD: 7-Amino-actinomycin D; ANOVA: Analysis Of Variance; CyA: Cyclosporine A; DMEM: Dulbecco's Modified Eagle Medium; FACS: Fluorescence-Activated Cell Sorting; FBS: Fetal Bovine Serum; FITC: Fluorescein Isothiocyanate; GVHD: Graft-Versus-Host-Disease; IL: Interleukine; IM: Intramuscular; IFN- $\gamma$ : Interferon Gamma; IP: Intraperitoneal; MLR: Mixed-Lymphocyte Reaction; MSCs: Mesenchymal Stem Cells; PBS: Phosphate Buffered Saline Solution; PE: Phycoeritrin; S.E.M.: Standard Error of the Mean

\section{Introduction}

Immunomodulation in clinical transplantation should prevent rejection of the allograft as well as the toxicity of long-term immunosuppressive drug treatment. In recent years attention has focused on the therapeutic application of mesenchymal stem cells in an attempt to improve graft survival and achieve immunological tolerance [1] without pharmacological immunosuppression.

Mesenchymal Stem Cells (MSCs) are bone-marrow-derived pluripotent cells, capable of differentiating into multiple lineages $[2,3]$. Although the frequency of these cells in the bone marrow is very low, they can be isolated by simple procedures and expanded, maintaining their ability to differentiate into multiple lineages. MSCs do not express the hematopoietic markers CD34, CD45 or CD14, and can be identified by positive staining for a number of non-specific surface adhesion molecules such as CD29, CD44, CD73 and CD1059 [3]. Human MSCs do not express costimulatory and MHC class II molecules, which might be why they escape the immune system in vitro [4] and are considered good candidates for cellular therapy in an allogeneic setting [5]. MSCs are able to affect immune response both in vitro and in vivo; recent studies indicate that they suppress T-cell-mediated responses involved in tissue rejection $[4,6-9]$.
Many in vitro studies demonstrate that MSCs from various species can exert an immunoregulatory function and suppress T-cell proliferation, in autologous and alloreactive conditions, in response to various stimuli with cell contact-dependent and -independent mechanisms $[4,10]$. Emerging data indicate that MSCs act through interaction with a broad range of immune cells: T-lymphocytes, B-lymphocytes, natural killer cells and dendritic cells [11-14]. Moreover, MSCs suppress T-lymphocyte proliferation when added to a Mixed-Lymphocyte Reaction (MLR) [15].

Further support for their in vivo immunosuppressive features are the observations that allogeneic MSCs may prolong skin allograft survival in immunocompetent baboons [15], prevent the rejection of allogeneic B16 mouse melanoma cells in immunocompetent mice [16], and attenuate Graft-Versus-Host Disease (GVHD) in mice and humans $[17,18]$.

Given the ability of MSCs to act through multiple mechanisms, they have been used to prevent rejection in solid organ transplantation. Indeed MSCs can simultaneously exert antiinflammatory, vascular

${ }^{*}$ Corresponding author: Prof. Longoni Biancamaria, MD, PhD, Department of Oncology, Transplantation and Advanced Technology in Medicine, University of Pisa, Via Paradisa 2, 56124, Pisa, Italy, Tel: +39050996918; Fax: +39050543692; E-mail: biancamaria.longoni@med.unipi.it

Received October 08, 2011; Accepted December 12, 2011; Published Decembe 17,2011

Citation: Longoni B, Szilàgyi E, Puviani L, Mazzanti B, Paoli GT, et al. (2012) Mesenchymal Stem Cell-Based Immunomodulation in Allogeneic Heterotopic Heart-Lung Transplantation. J Transplant Technol Res 2:107. doi:10.4172/2161 0991.1000107

Copyright: ( 2012 Longoni B, et al. This is an open-access article distributed under the terms of the Creative Commons Attribution License, which permits unrestricted use, distribution, and reproduction in any medium, provided the original author and source are credited. 
and regenerative effects in transplantation, like most conventional pharmacological immunosuppressants.

MSCs have been successfully employed in several clinical trials, and in many animal models of transplantation have been shown to prolong graft survival [19]; nevertheless, in vivo studies on preclinical organ transplantation models $[15,20-26]$ have yielded conflicting results.

The aim of our work is to study the effect of MSCs on the rejection control of solid organ transplantation on a preclinical model of heterotopic heart-lung transplantation in rats. This experimental model investigated the effect of intravenous MSC infusion and compared it with immunosuppression induced by Cyclosporine A (CyA).

\section{Methods}

\section{Animals}

In this study male Wistar rats were utilized as the heart and bonemarrow donors, and male Sprague-Dawley rats as the recipients. They weighed between 250 and $275 \mathrm{~g}$. The animals were purchased from Charles River Laboratories, Italy, fed standard rodent chow (Rieper, Italy) and water both given ad libitum under a $12 \mathrm{~h}$ light/dark cycle. All the animal procedures were carried out with the approval of the University of Pisa's Ethical Committee for Animal Use and Care.

\section{Experimental design}

We performed a study to assess the effect of intravenous administration of MSCs in rats undergoing heterotopic heartlung allograft transplantation. The experimental design comprised four groups, which underwent heterotopic heart-lung allograft transplantation as follows: control animals receiving heterotopic heart-lung transplantation alone (group $\mathrm{A}, \mathrm{n}=15$ ); animals receiving heterotopic heart-lung transplantation plus intravenous administration of MSCs (group B, $\mathrm{n}=25$ ); animals receiving heterotopic heart-lung transplantation plus CyA immunosuppressive treatment (group C, $\mathrm{n}=13$ ); and animals receiving heterotopic heart-lung transplantation plus immunosuppressive treatment combined with intravenous MSC administration (group D, $\mathrm{n}=13$ ).

\section{MSC and CyA administration protocol}

The Sprague-Dawley rats of groups B and D received Wistar MSCs in the tail vein on transplantation day. The administered MSC dose was $20 \times 10^{6} / \mathrm{kg}$ in $500 \mu \mathrm{l}$ of PBS-1x solution (SIGMA-ALDRICH, Italy) at day 0 .

The animals in groups $\mathrm{C}$ and $\mathrm{D}$ received intramuscular CyA (Sandimmun; Novartis, Novartis Pharma S.p.A., Varese, Italy) administration at a dose of $5 \mathrm{mg} / \mathrm{kg} / \mathrm{day} 24$ hours before transplantation.

\section{Rat MSC isolation, expansion and characterization}

Bone marrow cells were collected from the male Wistar rats using Dobson's procedure [27]. They were then re-suspended in culture medium (DMEM-Low Glucose, [Eurobio, Italy], supplemented with $10 \%$ FBS [Eurobio, Italy]), counted with a haemocytometer and seeded at $24 \times 10^{6} / 75 \mathrm{~cm}^{2}$ flask. Subsequently, the cells were incubated $\left(37^{\circ} \mathrm{C}\right.$ in a humidified atmosphere containing $95 \%$ air and $\left.5 \% \mathrm{CO}_{2}\right)$, expanded and characterized as previously described [26]. In vitro differentiation was performed by incubating MSCs in osteogenic and adipogenic medium. At the fourth or fifth passage, the morphologically homogeneous population of MSCs were analysed for the expression of particular cell-surface molecules (CD45-CyChrome ${ }^{\mathrm{TM}}$, CD11bFITC; CD90-PE, CD106-PE, CD73-PE, CD54-FITC, CD44-FITC, BD Pharmingen, San Diego, CA, USA) using FACScalibur (BD).

\section{Heterotopic heart-lung transplantation}

The recipients were anesthetized with Zoletil $100(10 \mathrm{mg} / \mathrm{Kg}$, Virbac s.r.l., i.p), while the donors were anesthetized with Penthotal Sodium $(75 \mathrm{mg} / \mathrm{Kg}$ i.p. Gellini International); heterotopic heartlung transplantation was performed as previously described $[28,29]$. The systemic injection of MSCs $\left(20 \times 10^{6} / \mathrm{kg}\right.$ diluted in $0.5 \mathrm{ml}$ PBS-1X solution, via the tail vein) was performed immediately after the heartlung transplantation. CyA was diluted in PBS-1X solution and injected i.m. at a dosage of $5 \mathrm{mg} / \mathrm{kg} / \mathrm{d} 24$ hours before transplantation. Heart grafts were checked daily and graft rejection time was defined as the day on which no cardiac contractions were detectable by abdominal palpation and direct laparotomic visualization of the allograft.

\section{Histological examination}

Animals were sacrificed at different time points after transplantation. The grafted heart and lung were excited, fixed in $4 \%$ formaldehyde solution and embedded in paraffin. For both organs, 5- $\mu \mathrm{m}$ sections were stained with haematoxylin-eosin for histological examination. A pathologist performed a blinded analysis to assess the intensity of rejection, and each sample was graded according to a coring system described by Billingham's standardized working formulation [30].

\section{Statistical analysis}

All the data were uploaded into a statistical analysis program (GraphPad Prism5.0, GraphPad software). Values are reported as mean \pm standard error of the mean (S.E.M.). Statistical analysis was conducted with the unpaired t-test; difference with $\mathrm{p}$ values $<0.05$ were considered significant. Kaplan-Meier analysis (Origin version 5.0 Professional [OriginLab ${ }^{\star}$, Northampton, MA]) was used to determine allograft survival in the MSC- and CyA-treated groups, and a comparison was made with the control group.

\section{Results \\ MSC characterization}

Rat bone marrow-derived MSCs were purified by plastic adherence. After the fifth passage, the cells grew exponentially, requiring weekly passages. MSCs treated with osteogenic medium formed small deposits of hydroxyapatite intensely red stained with Alizarin S (Figure 1a). Treatment with adipogenic medium differentiated MSCs towards adipogenic lineages with Sudan Black staining (Figure 1b). Cytofluorimetric analysis was used to assess the purity of the MSCs and the existence of a homogeneous population of adherent cells (after 4-5 passages). After the exclusion of dead cells ( $\mathrm{R} 1$ on 7-AAD negative elements, Figure 1c-d), the cell population was uniformly positive for CD90, CD44, CD54, CD73 and CD106. There was no significant contamination of hematopoietic cells, as flow cytometry was negative for markers of hematopoietic lineage, including CD11b and CD45 (Figure 1e-h).

\section{Effect of MSC administration on graft survival}

To study the effect of MSC administration on graft rejection in solid organ transplantation, we used a rat model of heterotopic heart-lung transplantation. In our model we performed heart-lung transplantation either just with MSCs or in association with CyA, and compared the effects with data obtained with pharmacological CyA treatment alone. In the control group (rats receiving heterotopic heart-lung transplantation alone), the mean allograft survival was $3.05 \pm 0.6$ days, because of acute rejection (Figure 2a). Systemic MSC administration $\left(20 \times 10^{6} / \mathrm{kg}\right.$, via the tail vein) prolonged graft survival up to $14.5 \pm 3.7$ days (Figure 2a); however, the treatment with MSCs resulted in a high post-infusion mortality rate $(\sim 50 \%)$ due to respiratory failure caused 
Citation: Longoni B, Szilàgyi E, Puviani L, Mazzanti B, Paoli GT, et al. (2012) Mesenchymal Stem Cell-Based Immunomodulation in Allogeneic Heterotopic Heart-Lung Transplantation. J Transplant Technol Res 2:107. doi:10.4172/2161-0991.1000107

Page 3 of 7

by pulmonary edema. The immunosuppressive therapy with CyA $(5 \mathrm{mg} / \mathrm{kg}$, i.m.) prolonged graft survival up to $21.75 \pm 3.5$ days after transplantation, while the combined therapy (CyA + MSCs) increased graft survival to $18.25 \pm 4.9$ days (Figure $2 \mathrm{a}$ ).

These results show that all the above-mentioned treatments were able to improve graft survival compared to the control groups, though CyA treatment proved to be the most efficacious. The Kaplan-Meier survival curve illustrated in Figure $2 \mathrm{~b}$ shows the loss of functionality over a period of 30 days. It is clear that acute rejection appeared in the first 5 days: in the control group, $100 \%$ of functionality was lost in this period, while in the group treated either with MSCs or CyA plus MSCs, survival increased by up to $60 \%$, with no significant statistical differences between these groups. It is worth noting that the treatment with CyA alone improved graft survival by up to $85 \%$ (Figure $2 \mathrm{~b}$ ).

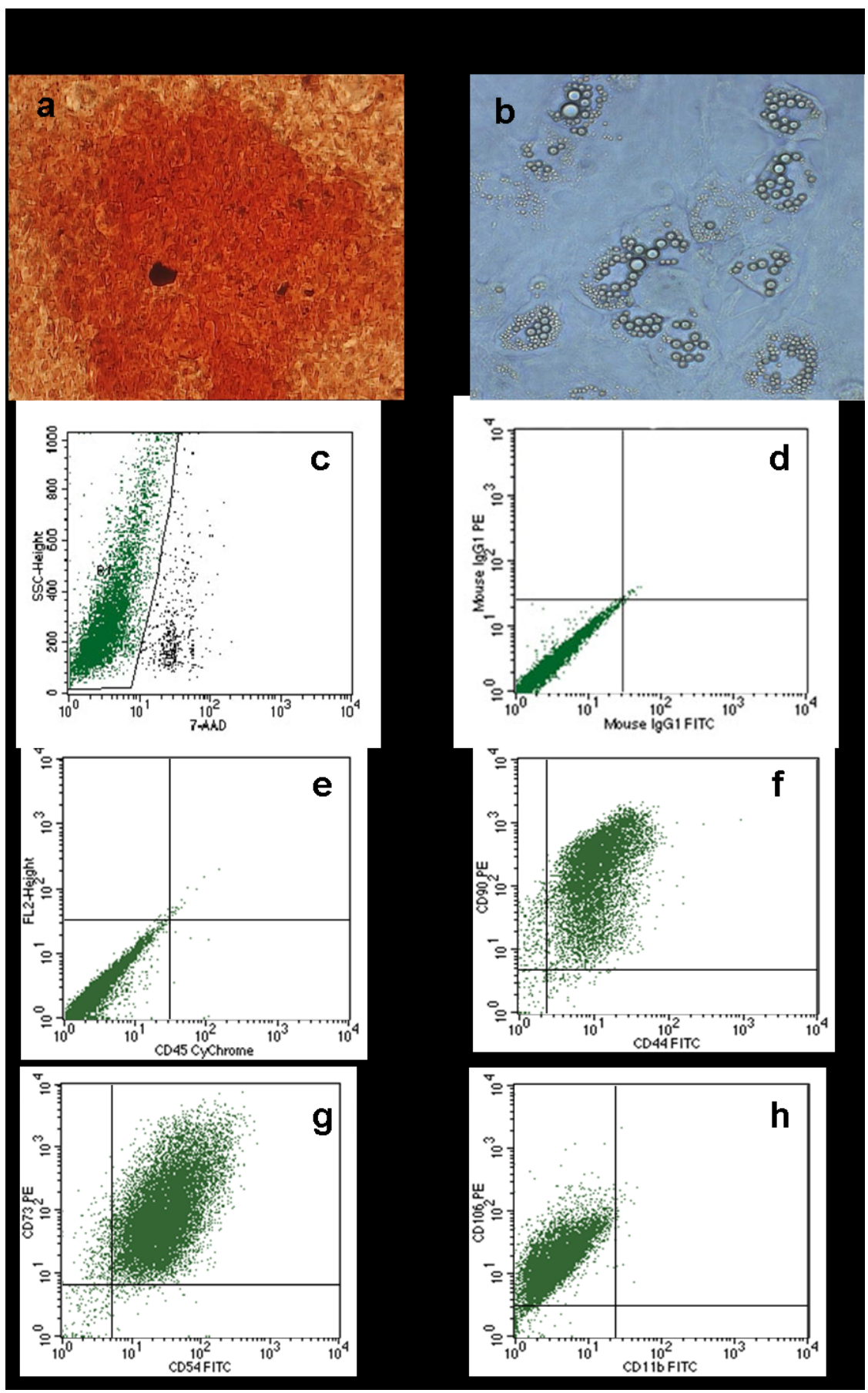

Figure 1: Characterization of MSCs. Differentiation into respective lineages was identified under specific conditions: deposits of hydroxyapatite intensely red stained with Alizarin S after culture in osteogenic medium (a), white lipid vacuoles of the cytoplasm of MSCs treated with adipogenic medium stained with Sudan Black (b). Flow cytometric analysis of surface adhesion molecules on rat MSCs. Cells positive to 7-AAD were discarded in order to exclude dead cells (c); isotype control IgG1 (d); cells were labelled with monoclonal antibodies specific for molecules indicated in each flow cytometric diagram: CD11b and CD45 antibodies showed no contamination of haematopoietic cells, while CD44, CD54, CD73, CD90 and CD106 were positive as classical mesenchymal markers (e-h). 
Citation: Longoni B, Szilàgyi E, Puviani L, Mazzanti B, Paoli GT, et al. (2012) Mesenchymal Stem Cell-Based Immunomodulation in Allogeneic Heterotopic Heart-Lung Transplantation. J Transplant Technol Res 2:107. doi:10.4172/2161-0991.1000107

\section{Histological analysis}

To evaluate the grade of rejection in this model, histological analysis was performed on the heart and lung allografts harvested 5 days after transplantation. Our results were expressed according to Billingham's standardized working formulation for heart and lung rejection [30].

We found that the heart rejection grade of the control group was uniform and classifiable as 3B (Figure 3a); the histology revealed the presence of diffuse small lymphocyte infiltrates with myocytic damage and perivascular edema, as showed in Figure 4.1a. Both the treatments with CyA and MSC infusion caused a reduction of acute rejection to $2 \mathrm{~B}$ (mean value, ${ }^{\star} \mathrm{p}<0.05$ vs. control, Figure $3 \mathrm{a}$ ). Histological evaluation of CyA and MSCs are showed respectively in Figure 4.1b and 4.1c. High variability was observed in the MSC grafts, and in some animals the grade of rejection was $1 \mathrm{~A}$, with focal interstitial infiltrates without myocyte damage (Figure 4.1c). Finally, the combined therapy of MSCs

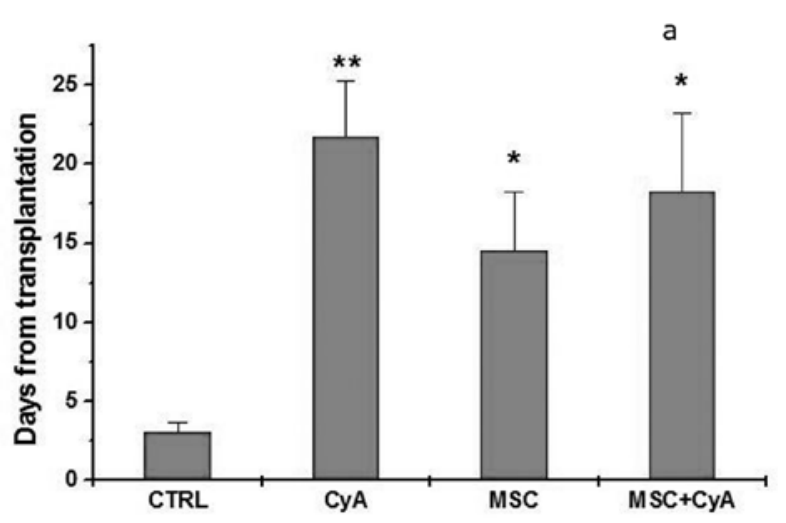

b

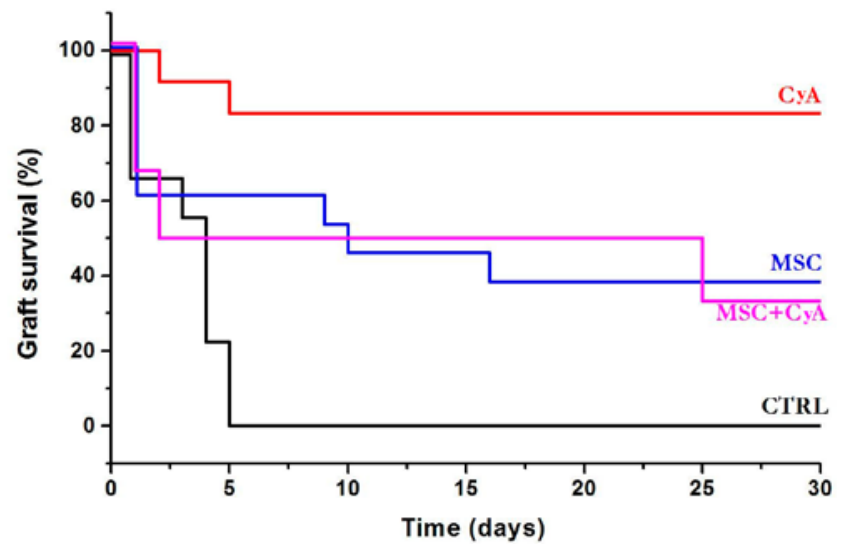

Figure 2: Graft survival. (a) Mean graft survival in the four groups: CTRL, control group receiving heterotopic heart-lung transplantation alone; CyA, receiving heterotopic heart-lung transplantation with daily administration of Cyclosporine A treatment ( ${ }^{* *} \mathrm{P}<0.01 \mathrm{vs}$. control); MSC, receiving heterotopic heart-lung transplantation with MSC infusion (* $P<0.05 \mathrm{vs}$ control); $\mathrm{MSC}+\mathrm{CyA}$, receiving heartlung transplantation with immunosuppressive treatment in combination with intravenous MSC administration ( ${ }^{*} P<0.05$ vs. control). (b) Kaplan-Meier survival curve. The differences in survival time over 30 days after heterotopic transplantation were observed for the four groups: CyA showed the highest survival probability (up to $85 \%, 5 \mathrm{mg} / \mathrm{kg}$ daily, $\mathrm{n}=13)$; the probability for both the MSCs $\left(20 \times 10^{6} / 0.5 \mathrm{ml}\right.$ at day 0 , $\mathrm{n}=25$ ) and MSC+CyA (MSCs $=20 \times 10^{6} / 0.5 \mathrm{ml}$ at day 0 plus $5 \mathrm{mg} / \mathrm{kg}$ daily, $n=13)$ fell to $60 \%$; the control group $(n=15)$ revealed a complete loss of graft functionality within the first 5 days.
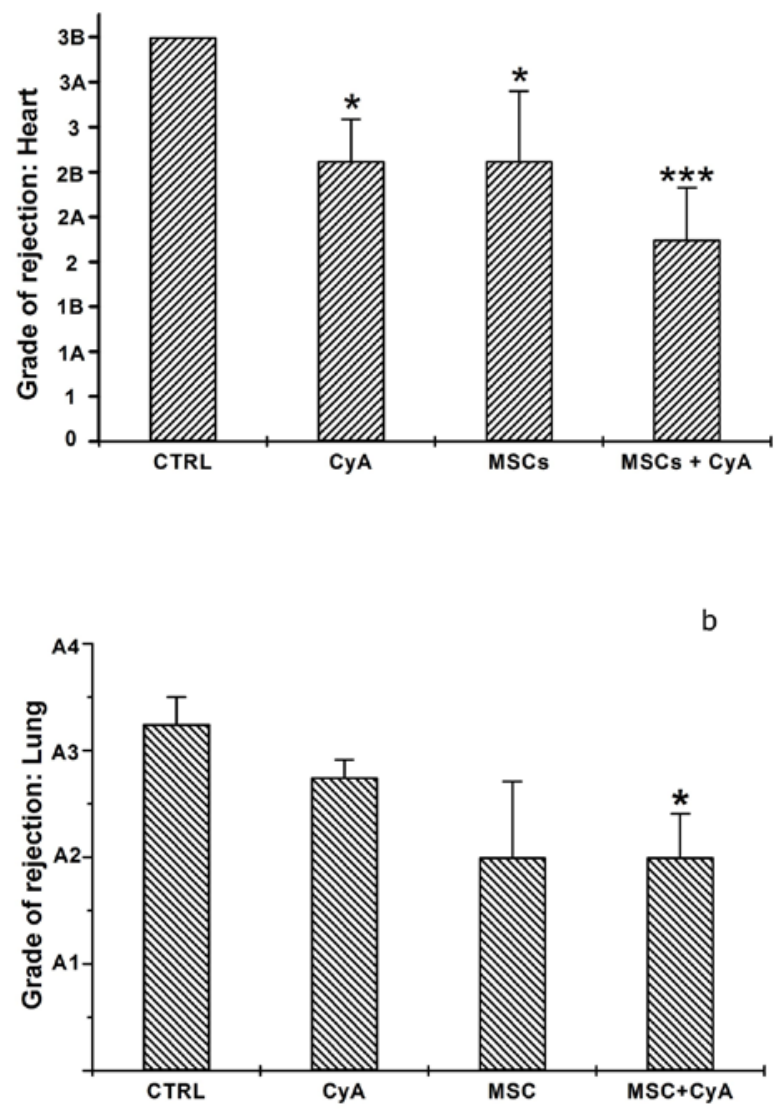

Figure 3: Grade of rejection. (a) Heart rejection grade. Control showed a $3 B$ level; both CyA and MSCs decreased to grade $2 B\left({ }^{*} p<0.05\right.$ vs. control); MSCs + CyA reported a statistically significant reduction to $2 / 2 \mathrm{~A}$ mean level ( ${ }^{* * *} p<0.001$ vs. control). (b) Lung rejection grade. Control showed mean values of A3/A4; CyA rejection was reduced to grade A2/A3; both MSCs and MSCs+CyA reported a decrease to level $A 2$, with a more statistically significant grade for the latter ${ }^{*} p<0.05$ vs. control).

plus CyA showed the lowest mean rejection level, 2/2A, with the highest statistically significant values ( ${ }^{* *} \mathrm{p}<0.001$ vs. control). As can be seen in Figure 4.1d, the heart histology of a recipient treated with MSCs plus CyA showed a rejection grade of $1 \mathrm{~A}$, with solitary perivascular infiltrates and normal myocytes.

Lung histological analysis showed similar results to that for the heart. The lung lobe, without breathing function, acts as a blood reservoir and in the space of a few days undergoes complete hepatization. In the control group, the mean grade of rejection was A3/A4 (Figure $3 \mathrm{~b}$ ), with the presence of diffuse perivascular, interstitial and alveolar infiltration composed by mononuclear cells; prominent pneumocyte damage and neutrophils infiltration were also present. Necrotizing vasculitis and endobronchial exutation were evident (Figure 4.2a). In the group of animals treated with CyA there was a reduction to the A2/ A3 level (Figure 3b). The histological evaluation showed a perivascular mononuclear infiltrate and expansion of the perivascular interstitium by inflammatory cells. Alveolar macrophage desquamation was also present (Figure 4.2b). Both immunosuppression with MSC infusion and the combined therapy (MSCs + CyA) reduced the rejection level to A2 compared to the controls (Figure 3b). The treatment with MSCs resulted in high variability and consequently the reduction was not statistically significant. The histology evidenced scattered mononuclear infiltrates and blood vessels cuffed by plasmacytoid cells 
Citation: Longoni B, Szilàgyi E, Puviani L, Mazzanti B, Paoli GT, et al. (2012) Mesenchymal Stem Cell-Based Immunomodulation in Allogeneic Heterotopic Heart-Lung Transplantation. J Transplant Technol Res 2:107. doi:10.4172/2161-0991.1000107

Page 5 of 7

and lymphocytes. In some cases, many alveolar spaces were devoid of cells, with a resulting A1 rejection grade (Figure 4.2c).

In the group treated with MSCs plus CyA the reduction of the rejection grade to A2 was statistically significant, as shown in Figure $3 \mathrm{~b}$ (mean value, ${ }^{*} \mathrm{p}<0.05$ vs. control). The histological data show that scattered mononuclear cells were present in the interalveolar septa; moreover, the alveolar morphology was well preserved as a consequence of minimal acute rejection (Figure $4.2 \mathrm{~d}$ ). In all the immunosuppressive treatments, lymphocyte infiltration in the parenchyma and inflammation were reduced.
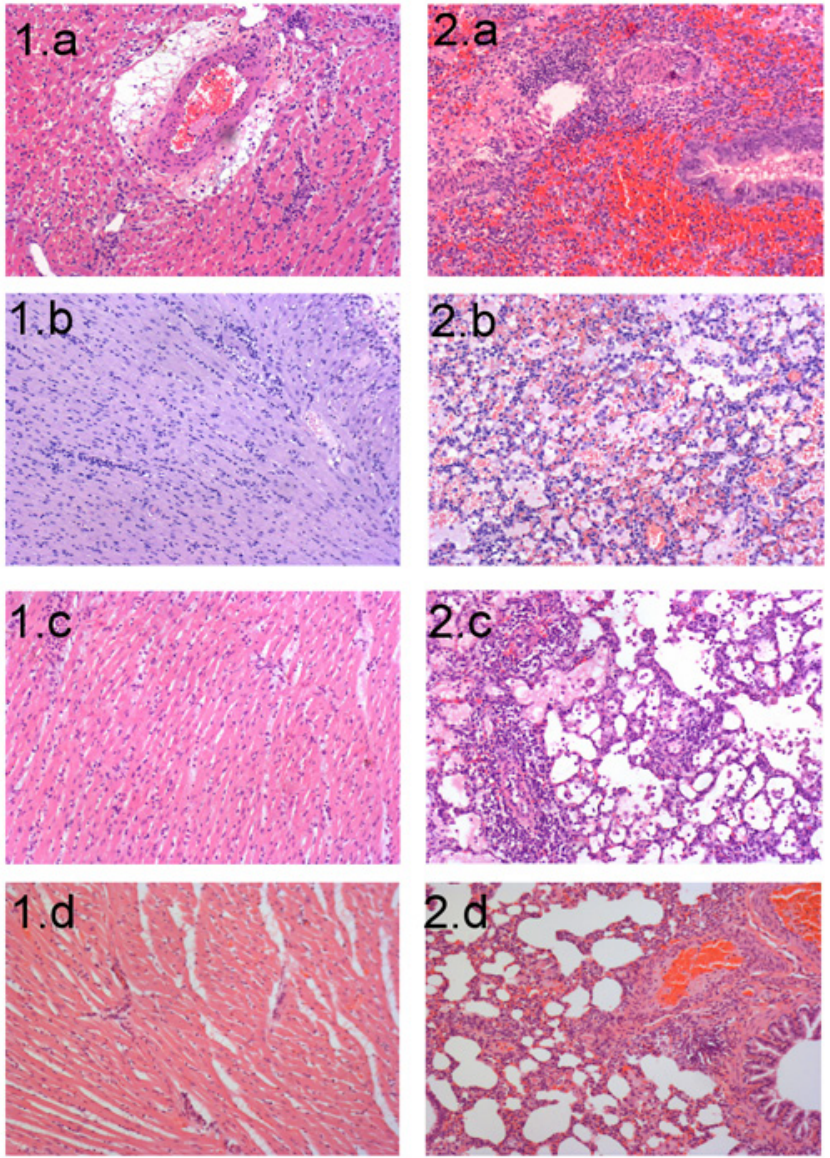

Figure 4: Histology of heterotopic heart-lung transplantation. Grafts were harvested five days after the transplantation and evaluated by Haematoxylin Eosin (x100 o.m.) staining of paraffin sections. 4.1 Heart histology: Control group (a): Diffuse small lymphocyte infiltrate with myocytic damage. Perivascular edema. Rejection grade: 3B; CyA group (b): Multifocal small lymphocyte infiltrate with scanty eosinophils. No evidence of myocyte damage. Rejection grade: $3 A$; MSC group (c): Focal interstitial infiltrates without myocyte damage. Rejection grade: 1A; MSCs plus CyA group (d): Low rejection grade represented by solitary perivascular infiltrates; myocytes are normal. Rejection grade: $1 \mathrm{~A}$.

4.2. Lung histology. Control (a) reported a A4 rejection grade with diffuse perivascular, interstitial, and alveolar infiltration composed by mononuclear cells; prominent pneumocyte damage, with haemorrhagic and neutrophilic infiltration. Necrotizing vasculitis and endobronchial exutation are also evident; CyA group (b): Perivascular mononuclear infiltrate and expansion of perivascular interstitium by inflammatory cells. Alveolar macrophage desquamation. Rejection grade: A2; MSC group (c): Scattered mononuclear infiltrates and blood vessels cuffed by plasmocytoid cells and lymphocytes. Many alveolar spaces are devoid of cells. Rejection grade: A1; MSC plus CyA group (d): small peribronchial inflammatory infiltrate; interalveolar septa contain scattered mononuclear cells, with empty alveolar spaces, as in minimal acute rejection. Rejection grade: $\mathrm{A} 1$.
Given the complete absence of histologic evidence of acute antibody-mediated rejection in all the cases (such as capillaritis in the lung and acute capillary injury with macrophages or neutrophils in heart capillaries), we did not evaluate the immunohistochemical expression of C4d according to the current protocols for graft evaluation. Furthermore, C4d antibody, a marker of antibody-mediated rejection in the kidney, may be of limited value in the lung because of the patchy nature and low sensitivity of C4d staining in the lung [31].

\section{Discussion}

MSCs have immunomodulatory effects and interact with the immune system. Because of these effects they are considered a promising option for the future development of clinical applications such as transplantation, in view of their role as immunosuppressants. Although the immunomodulatory effect of MSCs in vitro is well established, recent works have yielded conflicting results in in vivo studies on preclinical organ transplantation models [15,20-26]. In this work we studied the ability of MSCs to reduce acute rejection, either on their own or in combination with Cyclosporine A, in a model of heterotopic heart-lung transplantation.

Gao and colleagues have demonstrated that the distribution of mesenchymal stem cells in tissues is the same either by intravenous or intra-artery injection [32]. Consequently, we chose intravenous MSC administration. The dose used in our model, $20 \times 10^{6} / \mathrm{kg}$, is equivalent to $5 \times 10^{6}$ MSCs per animal, which is the maximum dose usable without causing emboli in the lung [15] and which is able to prolong skin graft survival in a baboon model after in vitro suppression of mitogen response, in a dose-dependent manner [6]. Our results showed that MSCs were indeed able to significantly prolong graft survival (14.5 \pm 3.7 days), compared to the untreated animals (3.05 \pm 0.6; control group). Nevertheless, a subtherapeutic dose of CyA (5 mg/ $\mathrm{kg}$ ) was more effective in prolonging graft survival (21.75 \pm 3.5$)$, while MSCs in combination with CyA showed a survival time similar to the CyA group (18.25 \pm 4.9 days). However, histological analysis showed that the MSC and MSC plus CyA treatments were more effective in reducing heart and lung rejection (respectively from $3 \mathrm{~B}$ to $2 \mathrm{~A} / 2 \mathrm{~B}$ and from $\mathrm{A} 4 / \mathrm{A} 3$ to $\mathrm{A} 3 / \mathrm{A} 2$ ), (Figure $3 \mathrm{a}, 3 \mathrm{~b}$ ).

According to the results of $\mathrm{Ge}$ et al. [33], our histological data showed that MSCs alone attenuate acute allograft rejection, but this treatment was not sufficient to completely inhibit the allogeneic response; indeed, scattered infiltrates were present in both the heart and lung. Histological data showed that the MSC treatment was more efficacious in reducing lymphocytic infiltration, although this was not accompanied by a parallel increase in post-transplant graft survival when compared to CyA treatment. In the combined therapy of MSCs plus CyA, an increase of the effect was observed (Figure 2a).

These results are in contrast with the findings of Inoue [15], who reported that MSCs were not only ineffective in prolonging graft survival, but also that when they were administered in combination with CyA graft rejection was accelerated. It is important to underline that the protocols used by Inoue differed from ours. Indeed, a higher dose of MSCs $\left(20 \times 10^{6} / \mathrm{kg}\right)$ was injected systemically (in the tail vein) in our experiments, while Inoue's group used lower doses. Moreover, in the combined treatment we used a ten-fold higher dose of CyA (5 $\mathrm{mg} / \mathrm{kg}$ ), administered daily and beginning with the first dose 24 hours before transplantation, versus $0.5 \mathrm{mg} / \mathrm{kg}$ from day 5 to 9 in Inoue's protocol.

It is our belief that the time gap in our protocol between the first injection of CyA and the MSC infusion is the ideal condition to enable 
Citation: Longoni B, Szilàgyi E, Puviani L, Mazzanti B, Paoli GT, et al. (2012) Mesenchymal Stem Cell-Based Immunomodulation in Allogeneic Heterotopic Heart-Lung Transplantation. J Transplant Technol Res 2:107. doi:10.4172/2161-0991.1000107

Page 6 of 7

MSCs to engraft and to exert their immunosuppressive function; this is similar to the effect found by Ge et al. [33] for the combined treatment MSCs plus Rapamycin.

Many works report that CyA inhibits IFN- $\gamma$ production by $\mathrm{T}$ cells $[34,35]$ and the activation of MSCs, thus preventing the immunomodulatory effect of MSCs [36-43]. Nevertheless, Kim observed that autologus MSCs plus CyA down-regulate immune response in a rat islet transplantation model by reducing the production of pro-inflammatory cytokines, IL-2, IFN- $\gamma$, and increasing anti-inflammatory cytokine production, especially IL-4 and IL-10 [19]. Similarly, in our previous work on islet transplantation, we observed a reduction of pro-inflammatory cytokines (IFN- $\gamma$, GM-CSF) in animals treated with MSCs [44]. We therefore hypothesize that an analogous decrease in pro-inflammatory cytokines may be part of the mechanism relating to the control of acute rejection in heterotopic heart-lung transplantation. MSCs induce a down-regulation of IFN- $\gamma$, the main cytokine secreted by CD4+ and involved in the recruitment and/or activation of other inflammatory cells in allograft rejection. The presence of high levels of IFN- $\gamma$ is a necessary requirement for CD4+ T cell-mediated acute allograft rejection [45]. The role for CD4 T cells in acute heart allograft rejection is well established.

In conclusion, our data demonstrate that allogeneic MSCs are able to prolong graft survival in a rat heterotopic heart-lung transplantation model as observed in a rat islet transplantation model [44]. Moreover, MSCs administered in combination with CyA showed an increased efficacy compared to both cellular and pharmacological treatment alone.

The existence of conflicting data regarding the use of MSCs in solid organ transplantation is such that further studies are required to understand the underlying mechanism of action and the precise role of these cells in increasing graft survival. Enhanced knowledge of these mechanisms will be of enormous help in the development of future clinical applications.

\section{Acknowledgment}

This work was supported by grants from Regione Toscana and from the ARPA Foundation

\section{References}

1. Fehr T, Sykes $M(2004)$ Tolerance induction in clinical transplantation. Transpl Immunol 13:117-130.

2. Friedenstein AJ, Petrakova KV, Kurolesova AI, Frolova GP (1968) Heterotypic transplants of bone marrow: analysis of precursor cells for osteogenic and hematopoietic tissues. Transplantation 6:230-247.

3. Pittenger MF, Mackay AM, Beck SC, Jaiswal RK, Douglas R, et al. (1999) Multilineage potential of adult human mesenchymal stem cells. Science $284: 143$ 147

4. Tse WT, Pendleton JD, Beyer WM, Egalka MC, Guinan EC (2003) Suppression of allogeneic T-cell proliferation by human marrow stromal cells: implications in transplantation. Transplantation 75:389-397.

5. Le Blanc K, Ringden O (2005) Immunobiology of human mesenchymal stem cells and future use in hematopoietic stem cell transplantation. Biol Blood Marrow Transplant 11:321-334.

6. Bartholomew A, Sturgeon C, Siatskas M, Ferrer K, McIntosh K, et al. (2002) Mesenchymal stem cells suppress lymphocyte proliferation in vitro and prolong skin graft survival in vivo. Exp Hematol. 30:42-48.

7. Di Nicola M, Carlo-Stella C, Magni M, Milanesi M, Longoni PD, et al. (2002) Human bone marrow stromal cells suppress T-lymphocyte proliferation induced by cellular or nonspecific mitogenic stimuli. Blood 99: 3838-3843.

8. Le Blanc K, Tammik C, Sundberg B, Haynesworth S, RingdénO (2003) Mesenchymal stem cells inhibit and stimulate mixed lymphocyte cultures and mitogenic responses independently of the major histocompatibility system. Scand J Immunol 57:11-20.

9. Mclntosh K, Bartholomew A (2000) Stromal cell modulation of the immune system. Graft 3:324-328.

10. Rasmusson I, Ringden O, Sundberg B, Le Blanc K (2005) Mesenchymal stem cells inhibit lymphocyte proliferation by mitogens and alloantigens by different mechanisms. Exp Cell Res 305:33-41.

11. Stagg J, Galipeau J (2007) Immune plasticity of bone marrow-derived mesenchymal stromal cells. Handb Exp Pharmacol 180:45-66.

12. Noel D, Djouad F, Bouffi C, Mrugala D, Jorgensen C (2007) Multipotent mesenchymal stromal cells and immune tolerance. Leuk Lymphoma 48:12831289.

13. Ramasamy R, Fazekasova H, Lam EW, Soeiro I, Lombardi G, et al. (2007) Mesenchymal stem cells inhibit dendritic cell differentiation and function by preventing entry into the cell cycle. Transplantation 83:71-76.

14. Nauta AJ, Fibbe WE (2007) Immunomodulatory properties of mesenchymal stromal cells. Blood 110:3499-3506.

15. Inoue S, Popp FC, Koehl GE, Piso P, Schlitt HJ, et al. (2006) Immunomodulatory effects of mesenchymal stem cells in a rat organ transplant model. Transplantation 81:1589-1595.

16. Djouad F, Plence P, Bony C, Tropel P, Apparailly F, et al. (2003) Immunosuppressive eVect of mesenchymal stem cells favors tumor growth in allogeneic animals. Blood 102:3837-3844.

17. Chung NG, Jeong DC, Park SJ, Choi BO, Cho B, et al. (2004) Cotransplantation of marrow stromal cells may prevent lethal graft-versus-host disease in major histocompatibility complex mismatched murine hematopoietic stem cell transplantation. Int J Hematol 4:370-376.

18. Le Blanc K, Rasmusson I, Sundberg B, Gotherstrom C, Hassan M, et al. (2004) Treatment of severe acute graft-versus- host disease with third party haploidentical mesenchymal stem cells. Lancet 363:1439-1441.

19. Kim YH, Wee YM, Choi MY, Lim DG, Kim SC, et al. (2011) Interleukin (IL)-10 induced by $\mathrm{CD} 11 \mathrm{~b}(+)$ cells and IL-10-activated regulatory T cells play a role in immune-modulation of mesenchymal stem cells in rat islet allografts. Mol Med 17:697-708

20. Zhou HP, Yi DH, Yu SQ, Sun GC, Cui Q, et al. (2006) Administration of donor-derived mesenchymal stem cells can prolong the survival of rat cardiac allograft. Transplant Proc 38:3046-3051.

21. Wu GD, Nolta JA, Jin YS, Barr ML, Yu H, et al. (2003) Migration of mesenchymal stem cells to heart allografts during chronic rejection. Transplantation 75:679685.

22. Eggenhofer E, Renner P, Soeder Y, Popp FC, Hoogduijn MJ, et al. (2011) Features of synergism between mesenchymal stem cells and immunosuppressive drugs in a murine heart transplantation model. Transp Immunol 25:141-147.

23. Crop MJ, Baan CC, Korevaar SS, ljzermans JN, Alwayn IP, et al. (2009) Donorderived mesenchymal stem cells suppress alloreactivity of kidney transplant patients. Transplantation 87:896-906

24. Casiraghi F, Azzollini N, Cassis P, Imberti B, Morigi M, et al. (2008) Pretransplant infusion of mesenchymal stem cells prolongs the survival of a semiallogeneic heart transplant through the generation of regulatory $\mathrm{T}$ cells. $\mathrm{J}$ Immunol 181:3933-3946.

25. Popp FC, Eggenhofer E, Renner P, Slowik P, Lang SA, et al. (2008) Mesenchymal stem cells can induce long-term acceptance of solid organ allografts in synergy with low-dose mycophenolate. Transpl Immunol 20:55-60.

26. Sbano P, Cuccia A, Mazzanti B, Urbani S, Giusti B, et al. (2008) Use of donor bone marrow mesenchymal stem cells for treatment of skin allograft rejection in a preclinical rat model. Arch Dermatol Res 300:115-124.

27. Dobson KR, Reading L, Haberey M, Marine X, Scutt A (1999) Centrifugal isolation of bone marrow from bone: an improved method for the recovery and quantification of bone marrow osteoprogenitor cells from rat tibiae and femurae. Calcif Tissue Int 65:411-413.

28. Fox U, Montorsi M (1980) A technical modification of heart-lung transplantation in rats. J Microsurg 1:377-380.

29. Lee S, Macedo AR, Curtis GP, Lee D, Orloff MJ (1982) A simplified model for heterotopic rat heart transplantation. Transplantation 33:438-442. 
Citation: Longoni B, Szilàgyi E, Puviani L, Mazzanti B, Paoli GT, et al. (2012) Mesenchymal Stem Cell-Based Immunomodulation in Allogeneic Heterotopic Heart-Lung Transplantation. J Transplant Technol Res 2:107. doi:10.4172/2161-0991.1000107

Page 7 of 7

30. Billingham ME, Cary NR, Hammond ME, Kemnitz J, Marboe C, et al. (1990) A working formulation for the standardization of nomenclature in the diagnosis of heart and lung rejection: Heart Rejection Study Group. The International Society for Heart Transplantation. J Heart Transplant 9:587-593.

31. Stewart S, Fishbein MC, Snell GI, Berry GJ, Boehler A, et al. (2007) Revision of the 1996 working formulation for the standardization of nomenclature in the diagnosis of lung rejection. J Heart Lung Transplant 26:1229-1242.

32. Gao J, Dennis JE, Muzic RF, Lundberg M, Caplan Al (2001) The dynamic in vivo distribution of bone marrow-derived mesenchymal stem cells after infusion. Cells Tissues Organs 169:12-20.

33. Ge W, Jiang J, Baroja ML, Arp J, Zassoko R, et al. (2009) Infusion of mesenchymal stem cells and rapamycin synergize to attenuate alloimmune responses and promote cardiac allograft tolerance. Am J Transplant 9:17601772.

34. Reem GH, Cook LA, Vilcek J (1983) Gamma interferon synthesis by human thymocytes and T lymphocytes inhibited by cyclosporin A. Science 221:63-65.

35. Pereira GM, Miller JF, Shevach EM (1990) Mechanism of action of cyclosporine A in vivo. II. T cell priming in vivo to alloantigen can be mediated by an IL-2 independent cyclosporine A-resistant pathway. J Immunol 144:2109-2116.

36. Renner P, Eggenhofer E, Rosenauer A, Popp FC, Steinmann JF, et al. (2009) Mesenchymal stem cells require a sufficient, ongoing immune response to exert their immunosuppressive function. Transplant Proc 41:2607-2611.

37. Hoogduijn MJ, Crop MJ, Korevaar SS, Peeters AM, Eijken M, et al. (2008) Susceptibility of human mesenchymal stem cells to tacrolimus, mycophenolic acid, and rapamycin. Transplantation 86:1283-1291.
38. Hoogduijn MJ, Popp FC, Grohnert A, Crop MJ, van Rhijn M, et al. (2010) Advancement of Mesenchymal Stem Cell Therapy in Solid Organ Transplantation (MISOT). Transplantation 90:124-126.

39. English K, Barry FP, Field-Corbett CP, Mahon BP (2007) IFN-gamma and TNFalpha differentially regulate immunomodulation by murine mesenchymal stem cells. Immunol Lett 110:91-100.

40. Krampera M, Cosmi L, Angeli R, Pasini A, Liotta F, et al. (2006) Role for interferon-gamma in the immunomodulatory activity of human bone marrow mesenchymal stem cells. Stem Cells 24:386-398.

41. Crop MJ, Baan CC, Korevaar SS, ljzermans JN, Pescatori M, et al. (2010) Inflammatory conditions affect gene expression and function of human adipose tissue-derived mesenchymal stem cells. Clin Exp Immunol 162: 474-486.

42. Allison AC, Eugui EM (2000) Mycophenolate mofetil and its mechanisms of action. Immunopharmacology 47:85-118.

43. Ren G, Zhao X, Zhang L, Zhang J, L'Huillier A, et al. (2010) Inflammatory cytokine induced intercellular adhesion molecule- 1 and vascular cell adhesion molecule-1 in mesenchymal stem cells are critical for immunosuppression. J Immunol 184:2321-2328.

44. Longoni B, Szilagyi E, Quaranta P, Paoli GT, Tripodi S, et al. (2010) Mesenchymal stem cells prevent acute rejection and prolong graft function in pancreatic islet transplantation. Diabetes Technol Ther 12:435-446.

45. Wiseman AC, Pietra BA, Kelly BP, Rayat GR, Rizeq M, et al (2001) Donor IFNgamma receptors are critical for acute $\mathrm{CD} 4(+) \mathrm{T}$ cell-mediated cardiac allograft rejection. J Immunol 167:5457-5463. 